\title{
The Effect of Using Six Sigma Approach in Improving the Quality of Health Services in the Jordanian Ministry of Health
}

\author{
Ramzi Mubarak Al-tarawneh ${ }^{1}$ \\ ${ }^{1}$ Business Management, The World Islamic Sciences and Education University, Jordan \\ Correspondence: Ramzi Mubarak Al-tarawneh, Business Management, The World Islamic Sciences and \\ Education University, Jordan.
}

Received: September 20, 2019

Accepted: October 24, 2019 Online Published: November 8, 2019

doi:10.5539/ibr.v12n12p11

URL: https://doi.org/10.5539/ibr.v12n12p11

\begin{abstract}
This research aimed to examine the effect of using the Six Sigma approach with its sub-variables (management commitment and support, feedback and measurement, continuous improvement, processes and systems, human resources) on improvement quality of health services with its sub-variables (response, reliability tangibility) at Jordanian Ministry of Health at the top management level, to achieve the study objectives, a questionnaire was designed which consists of (48) items, used for collecting primary data from study sample (57) participant of top management level at the Ministry of Health, Accordingly the data were collected, analyzed, and hypotheses were tested using the Statistical Package for Social Sciences (SPSS), other statistical methods were used to achieve the study, The study finding revealed that: "There are a statistically significant impact at the level of significance $(\mathrm{P} \leq 0.050)$ of the Sigma Six standards and its sub -variables on the improvement of the Health services quality which presented ,by the Jordanian Ministry of Health, Based on such results the researcher recommended a number of recommendations, the most important one are :The Ministry of Health should introducing Sigma Six concept , standards, and implementing it at the top level management, and training all the employees at top management on sigma six, linking Sigma Six standards to ministry strategies, and provide all the necessary for that.

Conducting further studies that will show the positive effects of Six Sigma standards application in reducing the financial costs for health services, and working to applying these standards to the human resources management functions.
\end{abstract}

Keywords: Six Sigma standards, health service quality, ministry of health, top management

\section{Introduction}

The first decade of the twenty-first century witnessed a set of economic technological changes, that creation many challenges for organizations business, public and private sectors, including organizations specialized in health services, needing to develop itself and improve the quality of services provided to its customers, so they can gain an advantage to Their competitiveness with other organizations working in the same service sector, achieving their priority in growth, continuity and competition.

Health care organizations face many problems trying to satisfy their patients, whether in terms of their needs or expectations, employees motivation, intense competition, modern technology and high costs of health care, which obliged these organizations to find ways that are effective, useful for health institutions and patients and employees, and here comes Sigma Six the role as an effective tool that helps in obtaining accurate explicit data to prevent employees at higher administrative levels, from making their decisions based on personal judgments, Sigma Six reduces incorrect solutions, reduces the cost of the service.

Health care institutions are focusing their attention, on improving the safety and satisfaction of patients, because patients are, looking for quality as a condition for choosing a care service ,because there is no way that the quality of service is poor (defective), because it is sometimes a decisive factor between life and death. Six Sigma in Health Care, help improve the quality of patient care, and reduce waste and get rid of defects.

The health system in Jordan, like other health systems in the world, facing challenges related to comprehensive coverage of health services and financing, quality of services and governance in all its dimensions, and keeping pace with medical technology, information technology, which requires it to address these challenges in coordination, cooperation with other health sectors, to achieving the desired goals, and contribute effectively to 
Promote sustainable development in Jordan, in line with Jordan Vision 2025 and the National Health Sector Reform Plan.

Achieving quality in any service process is no longer a luxury but a necessity for the continuation of this process and reaping the desired fruits, it was necessary to use the Six Sigma method as one of the methods of continuous development in which the Ministry of Health found a new method to improve the quality of its health services.

Based on his position and social responsibility, the researcher seeks to conduct this study to demonstrate the impact of using Six Sigma approach in improving the quality of health services in the Jordanian Ministry of Health at the top management level]

\subsection{Research Problem and Research Questions}

Jordan take a place at middle regional location making it the first attention from the Arab countries, a good medical reputation that exceed surrounding countries, made it the first tourist destination in the Arab world, but Jordan has been exposed during the past years, to many international, regional pressures, which posed a challenge and burden, ministry hospitals, facilities, as a result of the refuge operations from neighbor countries, also government pressure and popular demands to develop and improve the quality of health care services.

The problem of the study was touched by the researcher, from his personal experience, through his working in the ministry of Health, there is a decline and disparity in the level of health service delivery between place and another therefore there is a lack of knowledge about Sigma six approach by employees at top management levels, and awareness of its importance, in improving the quality of health service in case It was applied in the Ministry of Health, therefore the importance of the study coming from answering the following key question:

1. What is the effecting by using Six Sigma methodology in improving the quality of health services provided by the Ministry of Health?

2. The main question has emerged from the following sub-questions:

- What is the possibility of using the Six Sigma standers at the higher administrative levels in the Ministry of Health?

- What is the importance of Sigma Six in improving the quality of health service?

\subsection{Significant and Contribution}

The importance of the study lies in its originality, it is considered the first of its kind in Jordan, which studied the use of Sigma Six methodology in the health services sector, specifically the Ministry of Health - as far as the researcher is aware - and that most studies have addressed, this issue in the industrial, academic establishments, and health institutions in the private sector, The importance of the study as the following:

\subsubsection{Scientific Importance}

By providing a scientific addition about the variables of the study and provides ,a theoretical framework, that addresses those variables, linking its results with the results of previous studies, and to know the extent of agreement or disagreement, with them and to propose further studies in the future.

\subsubsection{Practical Importance}

The study draws its importance from the variables that dealt with, Sigma Six standers, and its impact on improving the quality of health services provided by the Ministry of Health, through a field study that leads to a set of results, conclusions and recommendations, that will be placed in the hands, of decision makers to benefit from them.

\subsection{Study Objectives}

This study is the first of its kind, according to the knowledge of researcher, which dealt with Sigma Six methodology in measuring the quality of health services in the Ministry of Health, the following objectives are set:

1 - Identify the effect of implementing Sigma Six standers at Ministry of Health through five main axes that considered as the requirements of applying the Sigma Six standers(commitment and Support of top management, continuous improvement, availability of necessary human resources, operations and information systems, feedback and measurement).

2 - Contribution to increase knowledge, and perception of this modern concept at the level of top management to improve the quality of health services provided. 


\section{Literature Review}

\subsection{Introduction}

[As a result of the great developments in the field of management, and continuous change, in the work environments that imposed, many administrative concepts, whether new, or existing, but need to develop commensurate with the change experienced by organizations, and these concepts (Six Sigma), this concept has achieved widespread, It was first introduced by Motorola in the 1980s, which began using this method to express its quality program. It was also used by many international companies, such as General Electric, Sony and Ford, and achieved success in providing millions of States S correct application of the Six Sigma approach]

\subsubsection{Six Sigma Concept}

Sigma is a Greek symbol used as a standard to measure standard deviation, or dispersion of any phenomenon, whether physical, chemical, service, and dispersion often causes, a departure from the typical values required of that phenomenon. (Awad, 2012)

The term Sigma Six expresses that $99.99966 \%$ of production is not defective or rather 3.4 million is only defective while the 1 Sigma expresses that $31 \%$ of production is defective production.

As for the number six "6" it symbolizes a level of "Sigma," where there are several levels of Sigma as shown in the table below where the greater the number accompanying Sigma, this indicates an increase in the level of quality and decrease the percentage of defects in the product and vice versa, This is true and there are segments that use eight sigma instead of six such as the airline sector, and the ophthalmology sector.

Table 1. Sigma levels, defects and payoff

\begin{tabular}{|c|c|c|}
\hline Defects Sigma levels & million chance of \% & return \\
\hline 1 & 691.462 & $\% 68.27$ \\
\hline 2 & 308.538 & $\% 95.45$ \\
\hline 3 & 66.807 & $\% 9.73 \%$ \\
\hline 4 & 6.214 & $\% 99.9937$ \\
\hline 5 & 233 & $\% 99.999940$ \\
\hline 6 & 3.4 & $\% 99.9999998$ \\
\hline
\end{tabular}

Source: ( Salaymeh , 2007)

There are many six Sigma definitions all around one content:

-Sigma Six: (a process or strategy that enables enterprises to improve significantly in terms of their core operations, through the design and control of daily business activities, and reduce waste, and consumption of resources, while at the same time to meet the needs of the client and to satisfy him. (Nasr, 2009)

-Sigma Six: An administrative philosophy, contributing to problem solving and devising ways to improve both process and performance, through the recognition and / or elimination of unnecessary goods and services and loss of jobs and activities and can be described as a tight application of a wide range of statistical and non-statistical skills and methods to reduce The size of the resulting contrast in any given process. ( Nazer , 2017)

-Sigma Six in the health sector: It is a regular statistical process to detect and address defects in performance, using the method of Sigma Six to reduce clinical bottlenecks and mechanism that leads to prolong time and high costs and bad results (Noor et al., 2012).

The definition according the researcher in the health sector refers to the "process analysis of technical processes to raise the level of quality of health care, and in accordance with the requirements of the patient."

\subsubsection{Sigma Six Curriculum Criteria}

-Six Sigma Approach : A clear methodological constructive strategy that includes a number of proven statistical and administrative tools such as illustrative maps are integrated in order to improve the quality of products or services by trained teams to apply this methodology .(Awad, 2011)

-Top management: Is the body responsible for setting the objectives and policy of the organization and long-term strategic planning and linking the organization with the environment and decision-making key governance and crisis management. (Abu Nasr, 2009)

-Feedback and Measurement: Provides feedback on quality programs staff performance continuously, allowing 
for improved processes to raise the level of quality, contribute to the opportunities of excellence, creativity and success of the organization and the engagement of its customers. (Abdul Rahim, 2014)

-Continuous Improvement: A never-ending-process that aims to make modifications to processes and work methods to improve the quality of outputs, with the aim of achieving perfection through continuous improvement of business and production processes . (Sanjak , 2010)

-Human resources: efficient human resources required before the implementation of the Six Sigma (or during it in any organization), trained in the management operations, analysis of customer requirements , and statistical tools in dealing with problems and linking the Six Sigma approach (promotions, incentives and rewards) Senior management to successfully apply this approach .(Jaber, 2015)

-Operations and systems: Includes a set of operations and activities carried out by the organization with the aim of providing service to customers.

\section{Six Sigma Basic Principles}

\subsection{Principles of Sigma Six}

Sigma Six is based on six principles according to: (Al-Otaibi, 2017)

Principle 1: Customer Focus.

The performance measurements at Sigma Six begin with the internal client "employees" and the external client "beneficiaries" because it is the first priority for the success, and continuity of the organization, so the institution is required to strive to meet the needs, and expectations of the client taking into account the continuous change of their needs and expectations.

Principle 2: Knowledge Management.

By focusing on solving its problems by building performance standards, and analyzing problems for decision-making based on scientific facts through data and information.

There are three main groups to choose the most suitable tools for solving problems through Sigma Six:

- -Team tools through responsibilities network and hands-on training.

- -Process development tools such as brainstorming, Pareto map, cause and effect analysis, and experimental design.

- -Statistical tools such as variance analysis, standard deviation, and graphs.

Principle 3: Focus on the Organization's operations and activities:

The term is intended to seek to prevent the problem before it occurs, to focus on how to address it, to review objectives on a continuous basis, to clearly identify priorities, and to avoid problems rather than remedy them after they have occurred.

Principle 4: Towards the Summit.

This requires meeting many conditions and requires management to have the ability to convince employees of the new changes that will occur and that this will affect them positively.

Principle 5: Unlimited Cooperation.

the elimination of administrative and psychological barriers, between the employees of the organization, and encourage ,and expand opportunities for cooperation ,between the internal groups of the organization instead of the spirit of competition, between them at all administrative levels with great care to encourage cooperation with the outside community.

Principle 6: Striving for perfection while allowing for error and continuous improvement:

The idea of continuous improvement stems from the principle of developing knowledge of the administrative and technical dimensions of the process and taking the necessary measures to develop to maintain the quality of performance and the application of new ideas and approaches to strive for perfection and excellence through Sigma Six.

\section{Six Sigma Characteristics}

The main objective of Sigma Six approach is to improve quality and efficiency, reduce waste in time, effort and energy ,and maximize profits, Sigma Six offers the benefit of companies in the form of profits, and value to the customer, and high quality products, and services at the lowest possible cost, thus companies can improve their competitive position, in the markets by reducing defects In this regard, the organizations are interested in the 
Sigma six method because of its characteristics, the most important are : - (Al-Rawi, 2011)

1. Access to permanent success: control of the market, innovation and continuous modernization in organizations and keep up with the administrative, technical, cultural developments appropriate to the success of constant and continuous in the competitive market.

2. Goal Setting: Sigma Six approaches focuses on the process and the client to set a fixed goal is to reach high performance as determined by Sigma Six approach or a level of performance close to perfection as expected by customers .(Al Nuaimi \& Sweiss, 2008)

3 Continuous Improvement: The philosophy of Sigma Six emphasizes the importance of continuous improvement for organizations, wishing to develop from the principle of developing knowledge, to reduce the administrative, and technical process and taking the necessary measures to develop, and to reduce the deviations that occur in the technical scientific which helps in maintaining the quality of performance and increase productivity. (Abdul Rahim, 2014)

4. Encourage training and learning: Sigma Six standers contributes significantly to the speed of implementation of tasks, and brainstorming, acquire new skills of staff with an emphasis on the willingness of each organization its members, to learn and continuous improvement, and thus the appreciation of these employees and motivated and rewarded.

5. Implementation of strategic change: the proper application of Sigma Six requires a full understanding of the operations teams, and procedures of the organization, as a way to achieve success in the work, especially with regard to the introduction of new products, or access to new markets, or the acquisition of new customers and must be linked to this approach to the strategies of the organization and long-term trends.

6. Focus on defects: Sigma six methods focus on defects and reduce the likelihood of their occurrence and this requires the identification of organizational processes clearly which helps in identifying the defect in the company's operations. (Abdul Rahim, 2014).

\section{The Benefits of Implementing Six Sigma}

The benefits of implementing Six Sigma approach are considered one of the most important reasons that led the major international companies to implement it's:

1. Rise in the level of revenue: through efficiency and the ability to provide services and products better and without errors, which reflects positively on revenue.

2. Reduce the costs borne by the establishment: Reduce the error rate in products and waste in resources in addition to saving time and effort.

3. Reducing the cost of poor quality: It is the costs related to the correction of errors after the occurrence, which is accomplished in a non-conformity and is called the cost of failure and there are two internal divisions before the product or service to the client and outside any arrival, and contribute to the application of the approach to reduce these costs.

4. Reducing the cost of production per unit: The role of the product in reducing errors or defects of products and services by taking advantage of the property of production in large quantities, which reduces the cost per unit.

\section{Six Sigma Theoretically}

\subsection{Organizational Structure of Six Sigma}

The quality of Sigma Six is customer-centric, everything starts and ends with the customer, that customers have the right to expect performance, reliability, prices, competitiveness, punctual delivery, service, clear and accurate processing of transactions, all of which requires a strong vision of what Six Sigma can achieve for the company, Freedom to explore new ideas, and concepts and the authority, and resources needed to make the decision to apply the approach in the work within the facility and requires management to start mobilizing members of the organizational structure of the team, to implement the Six Sigma standers, and also identifies the members of the team special tasks commensurate with His rank, named after the art of karate, is a martial arts art: such as the master black belt, the black belt, the green belt, and their roles can be illustrated as follows: (Omari, 2015)

1. Champion: The executive director of the Six Sigma project is called one of the tasks of the hero to manage individuals through change, determine the Six Sigma vision of the organization, and choose the project and the candidates to implement it.

The hero has other tasks, including the allocation of resources to the team to complete his work, set a schedule 
for the team to complete the project and evaluate the team's efforts, and also the necessary communications to move forward with the project and develop a road map for the implementation of Sigma Six.

2. Master Black Belt: Black Belt President participates the hero or sponsor of the project in some tasks, and has knowledge and understanding in the overall picture of the activity of the institution, and have a certificate of the Black Belt President, and the role of providing training and development at various levels of the institution, and help identify Projects, lead black belts in project work and support, participate in project reviews to provide technical expertise, assist in training and accreditation of black belts, assume key leadership programs, and facilitate the exchange of best practices in all organization facilities.

3. Black Belt: Black belt represents the person expert in the strategy of penetration, and the roles of several of the most important to identify obstacles and lead teams implementation of the project and guide, and reporting on each stage to the appropriate leadership levels.

4. Green Belt: The so-called trained employees who will lead the improvement teams, where they spend part of their time to complete the projects, but in return they will maintain their work and their basic responsibilities and can spend the green belt from 10 to $50 \%$ of their time on their projects and this depends on Their main business.

5. Yellow Belt (yellow belt): The yellow belt is called the project team members who work in Sigma six part-time projects part-time and yellow belt is the employee who received training in the basics of Sigma six during the full two or three days and has a greater understanding of the processes using Six Sigma tools and simple techniques.

6. Executive leader (implementation leader): It is the executive leader, where he carries out the full efforts of Sigma Six and usually holds the position of Vice President, which takes upon himself the development of Sigma Six vision within the framework of the company's business strategy, and his tasks are summarized in the following (remove obstacles and reduce resistance to change Encouraging others to respond to change, monitor results and share black belts in reviewing project outcomes, and must have strong leadership skills.

\section{Health Services}

\subsection{Health Service Concept}

The health service is the key to achieving health for all, and this has been confirmed by the Alma-Ata Declaration since 1977. It is also part of the development required to achieve social justice. It is the first contact of the people with the health care system. Although health services can be bought and sold, health cannot be traded. Good health is defined as a state of complete physical and mental health. Live and treat these problems if they occur.

\subsection{Health Service Characteristics}

The health services provided by hospitals have a number of characteristics that distinguish them from other services where the specificity of those services reflects the way in which the service can be provided to customers in terms of the following:- (Bakri, 2015)

1. The services of the hospital are characterized by being aimed at achieving a public benefit to various parties and beneficiaries, whether individuals or organizations.

2. The medical service is characterized by a high degree of quality because of its association with human life.

3. Government laws and regulations affect the operation of health institutions and hospitals, in particular, whatever their dependence.

4. Decision-making power in health organizations is somewhat distributed between management and physicians. Unlike business organizations, decision-making power is handled by one person or a group of people representing the power of management.

5. Health service can only be provided in the presence of the patient himself. This requires direct contact between the hospital and the beneficiary of the health service.

6. Because health services are linked to humans, they do not adopt the same standards as other services.

7. The fluctuation of demand for health services in the hours of the day or week requires the provision of health service to its applicants because it cannot apologize for the provision of those who need it

\subsection{Health Services Provided by the Jordanian Ministry of Health}

The Ministry of Health is one of the most important health sectors provide health services to citizens which concerned improving the quality of health services, continuing to work for all hospitals and health centers, to get 
accreditation, and to reduce the steady increase in the increasing rates of non-communicable diseases, and reduce their complications, strive to contribute to universal health coverage, Completing computing and electronic linking projects in addition to supporting all possible measures to contribute to the promotion of medical tourism, controlling spending and directing it towards priorities to contribute to stimulate economic growth and promote sustainable development. MOH, in line with the vision of Jordan 2025. (Ministry of health strategy,2018-2012)

\subsubsection{Types of Health Services Provided by the Jordanian Ministry of Health}

The Ministry of Health provides many services, including primary health care services, which are provided through a wide network of comprehensive, primary and secondary health centers, communicable and no communicable diseases, in addition to mental health and addiction services, reproductive health, health awareness and information programs, environmental and occupational health, and health. School, secondary and advanced health care, medical and nursing services, specialized, laboratory, ambulance, emergency, radiology services, blood transfusion. Pharmacy, quality and reliability .(strategy of ministry of health ,2018-2012)

\section{Health Service Quality}

\subsection{Health Service Quality Concept}

There are many definitions of the concept of quality and service, those who defined it as (a dynamic situation associated with physical products and services and individuals and processes and the surrounding environment to match expectations. (Al-dradka, 2002)

It has been defined by the British Standards Institute (BSI) "a set of qualities, features and properties of the product or service to satisfy and satisfy the urgent and necessary needs". (Abu El Nasr, 2009).

Accordingly, the quality as a simple concept refers to the quality of work and performance, which reflects positively on the client by obtaining his requirements and needs in the right form and quality required.

\subsection{Dimensions of the Quality of Health Services}

The dimensions of Sigma Six are divided into the following: (Issawi et al. 2018)

1. Continuous improvement: In the field of health services, it is an administrative philosophy aimed at continuously developing processes and activities related to machinery, tools, materials and personnel.

2. Response: In the field of health services, it means the ability, willingness and willingness of the service provider to continuously provide the service to the beneficiaries when they need it.

3. Reliability: means the ability of the health service provider (doctor, nurse, etc.) to perform the promised health service in a reliable manner.

4. Guarantee: In the field of health service is the result of accreditation or trust of patients with doctors and hospital staff, and confidence in their qualifications and ability.

5. Concrete: In the field of quality of health service, the following elements are included: Clean medical offices, hospital staff using standard means or machines, and prescriptions (medicines and medical supplies) should be easy to understand.

\section{Previous Studies}

(Alqatawneh et al,2019): “ Six sigma application in Healthcare logistics " a Framework and a Case Study aimed to develop a proposed, framework for how to apply Sigma Six in the scope of healthcare logistics" researchers have used the study methodology One of the most important findings of the study, was the selection of the Six Sigma project to improve healthcare logistics , one of the recommendations of the study was to use it to pave the way for further future research to clarify the ways in which Six Sigma is used in the field of improvement Health care Logistics.10

(Ahmad et al, 2017): "Effects of Six Sigma initiatives in Malaysian private hospitals" the studying aimed at applications of Six Sigma methodology, in Malaysian private hospitals, by measuring Six Sigma initiatives of private hospitals based on demographic composition such as Sex, Attitude and Work Experience Randomized stratified samples were used to collect data from eight hospitals, descriptive analysis and independent t-test and ANOVA samples were conducted in one direction using SPSS version 23, and from the results of this study, male respondents have a better perception of four aspects of Six Applications. Sigma such as process optimization tools, process optimization methods, Management of quality improvement activities and the formal planning process compared to the respondents, one of the most important recommendations is the continuous pursuit of knowledge in the field of Six Sigma using the strength of the relevant theories and basic principles of Six Sigma. 
(Khalil, et al, 2014): Requirement for implementing six sigma approach in "Jordanian pharmaceutical industry, This study aimed to prove the key factor in making the application of Sigma Six in pharmaceutical factories possible, the exploratory method was used by designing Questionnaire to collect information on the trends of managers in pharmaceutical manufacturing factories, the most important results of the study that the key factor is the support and commitment of senior management and its role in cultural change in this concept, and the most important recommendations of the study to provide adequate support to achieve the objectives of Sigma six in addition to the need to train and educate workers in this concept.

\section{Research Methodology}

\subsection{Study Hypothesis}

Based on the study questions, to achieving the desired objectives, the following hypotheses have been formulated:

\section{Main Hypothesis}

$\left(\mathrm{H}_{0} 1\right)$ : There is no statistically significant effect at the level of significance $(\mathrm{P} \leq 0.050)$ of the Sigma Six Approaches with its combined dimensions (commitment and management support, feed feedback and measurement, continuous improvement, processes and systems, human resources) in improving the quality of health services by its combined dimensions (response). (Reliability, Tangibility) in Jordanian Ministry of Health.

A number of sub-hypotheses emerge from this hypothesis:

1. $\left(\mathrm{H}_{0} 1-1\right)$ : There is no statistically significant effect at the level of significance $(\mathrm{P} \leq 0.050)$ of the Sigma Six methodology by its combined dimensions on the response in improving the quality of health services in the Ministry of Health.

2. $\left(\mathrm{H}_{0} 1-2\right)$ : There is no statistically significant effect at the level of significance $(\mathrm{P} \leq 0.050)$ of the Sigma Six curriculum standards by its combined dimensions on reliability to improving the quality of health services in the Ministry of Health.

3. $\left(\mathrm{H}_{0} 1-3\right)$ : There is no statistically significant effect at the level of significance $(\mathrm{P} \leq 0.050)$ of the Sigma Six approach criteria on tangibility to improve the quality of health services in the Ministry of Health.

\subsection{The Study Model}

Dependent variable

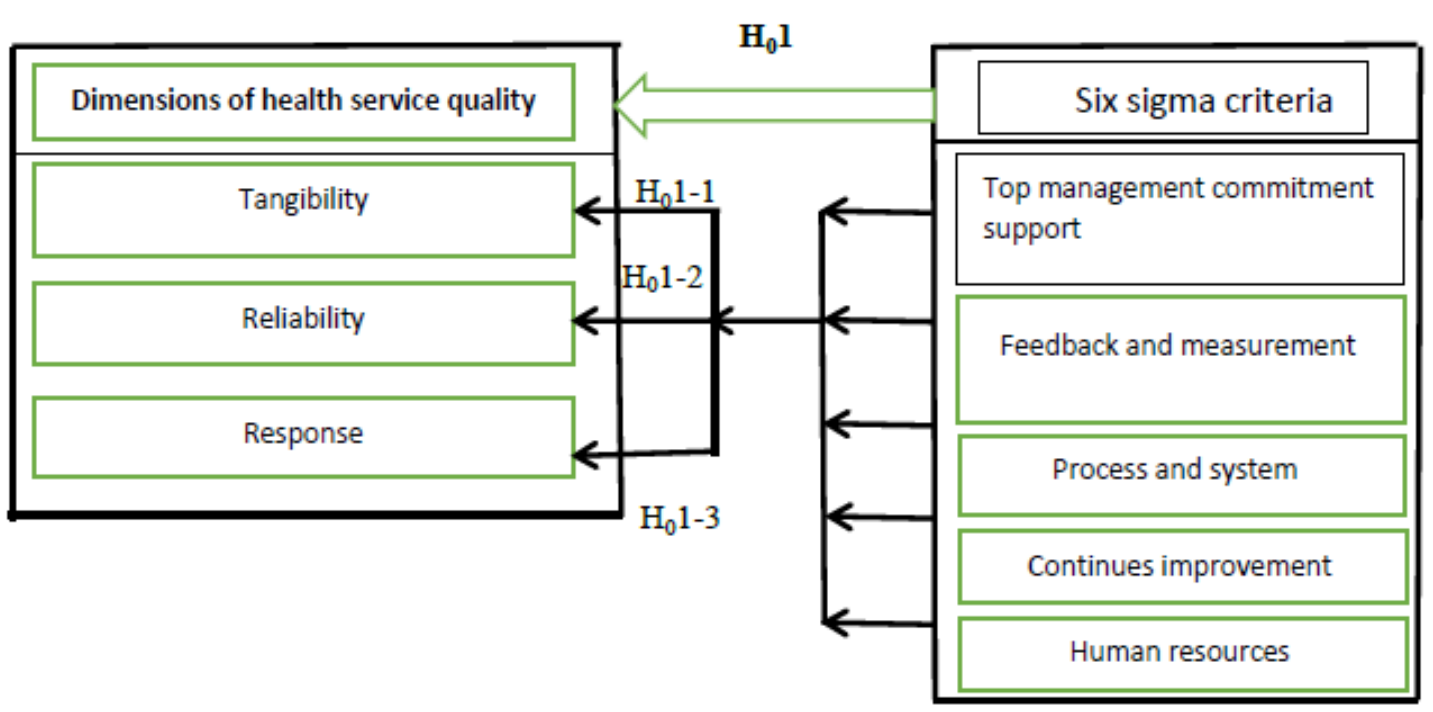

Figure 1. the study model

Figure (1) the study model prepared by the researcher based on the following references:

-Independent variable (Sigma six) : (Melhem, 2014), (Ahmed, 2017), (Naimi and Sweiss, 2008), (Tawfik, 2008) (Omari, 2011)

- The dependent variable (quality of services): (Taie et al., 2009) 


\subsection{Terms of Study / Procedural Definitions}

For the purposes of the present study, the procedural definitions of the dependent and dependent variable will be as follows:

-Six Sigma Approach: A quantitative approach to improve the quality of service in the Ministry of Health, by improving the leadership style, performance levels through the use of a number of mathematical equations to measure, determine the success of the Ministry of Health in its work.

- Top Management: It is the highest administrative levels in the Ministry of Health and concerned with planning, guidance, monitoring the overall results of the Ministry and the amendment of strategic plans.

- Feedback and Measurement: It is one of the evaluation methods used by the Ministry of Health to collect information on levels of performance and achievement, identify weaknesses and shortcomings and take corrective actions for errors and performance.

- Continuous improvement: One of the strategies followed by the Ministry of Health to improve its performance and, reduce waste in its resources, of time, expenses, operational costs, to achieve the highest levels of performance required.

- Human Resources: Human resources refers to the people working in the Ministry of Health, at various levels of management, where the Department of Human Resources is concerned with the management ,of these people through certain methods, and strategies that work to raise, the performance of employees and solve the problems of work and achieve the ministry 's desired objectives.

- Operations and systems: Includes a set of operations and activities carried out by the organization with the aim of providing service to customers.

- Quality of health service: The researcher believes that the quality of health service is represented by, a set of policies, procedures to provide health care services to the beneficiaries in a systematic, and objective manner and solve ,the problems in a scientific way, through the workers in health organizations, who use their skills and expertise and health care techniques available to them, to meet the needs of patients Ensures the best results at the right time and place at the lowest possible cost.

- Reliability: The reliability of the researcher's point of view indicates, the ability of the service provider organization ,to perform the service promised by the client, with a high degree of health, accuracy, time and performance.

- Quality: A set of characteristics enjoyed by the product that affects its ability to meet the stated and implied needs and the ultimate goal of service recipients' requirements and satisfaction.

- Concrete: The researcher means the physical facilities, associated with the provision of health service in the Ministry of Health, such as equipment, personnel, lighting, decoration, which is an influential element, in the patient's perception of the quality of service and build mental image of the service.

\subsection{Study Determinants}

Time Limits: The duration of the study procedures was determined in the summer semester of the academic year 2018/2019.

Spatial limits: the study is limited to senior management in the Ministry of Health.

Scientific Limits: The present study was limited to addressing the criteria of Sigma Six, represented by (commitment and support to management, feedback and measurement, continuous improvement, processes and systems, human resources) and the dimensions of the quality of health services ,represented by (reliability, response, tangibility).

\section{Sampling and Data Collection}

Type and nature of the study: The study used the descriptive analytical methodology as a method of data collection, illustrative in terms of purpose. Syllabus is considered in terms of time horizon because it takes place on a sample at one time.

Strategy used in research: The researcher used the survey or sampling strategy as one of the most commonly used strategies in human and social research, as it allows the collection of a large amount of data, and we can obtain standard data that allows easy comparison and enable us to quantify them using descriptive statistics to reach the relationships between variables. (Najjar et al., 2018) 


\section{Sample Study}

Study community: The study community consists of all employees at the top level of management in the Jordanian Ministry of Health (Center) and the number (57) employees.

Sample of the study: The researcher adopted Comprehensive survey method so that it is representative of each element of society without bias of the researcher due to the limited study population, the researcher has followed the method of comprehensive survey by distributing the questionnaire to all vocabulary of the study where the (57 A questionnaire distribution on all employees in the administration, who holds a job title manager and director of the Department and Assistant Secretary-General and the number of (57) employees and 41 questionnaires were recovered, about (0.719) $\%$ Of the study sample]

Analysis Unit: The analysis unit consisted of employees at the higher administrative levels in the Jordanian Ministry of Health, where the data were analyzed using SPSS and using the following tests:

- Cronbach Alpha Coefficient to ensure the reliability and stability of the scale.

- Analysis of multiple linear regression and descriptive statistics (arithmetic mean, standard deviation, iterations and percentages.

- Data Collection Method (Study Tool):

- The researcher adopted the descriptive analytical method, the method of study applied and adopted several methods to collect the necessary data represented by the following:

- Secondary data: The data related to the subject of the study was collected through books, references, studies, previous research, letters and theses related to the subject of the study.

- Preliminary data were collected through a field study based on a questionnaire designed for the purposes of the study using the Likert scale which divided to.

Section I: Demographic data of the respondent.

Section II: paragraphs of the questionnaire and divided into two dimensions (48) paragraphs distributed as follows:

The first dimension: It was represented by a set of questions related to the standards of Sigma Six (namely, support and commitment of senior management, reverse feeding and measurement, continuous improvement, processes and systems, human resources) about (30) paragraph.

The second dimension: It was represented by questions associated with the dimensions of the quality of health services and divided into (response, tangibility, reliability) about (18) paragraph.

\section{The Relevance of the Study Model to the Statistical Methods Used}

To test the suitability of the study model, linear regression analysis and parameter tests, multiple linear correlation and autocorrelation, multicollinearity were tested as follows:

\subsection{Multicollinearity Test}

This phenomenon indicates that there is an almost complete linear correlation between two or more variables, which amplifies the value of the R2 coefficient and makes it greater than its actual value.

Table 2. correlation matrix of independent variables

\begin{tabular}{|c|c|c|c|c|c|}
\hline $\begin{array}{c}\text { Operation } \\
\text { and } \\
\text { systems }\end{array}$ & HR & $\begin{array}{c}\text { Continues } \\
\text { improvement }\end{array}$ & $\begin{array}{c}\text { Feedback and } \\
\text { measurement }\end{array}$ & $\begin{array}{c}\text { Management } \\
\text { commitments and } \\
\text { support }\end{array}$ & Variable \\
\hline \multirow{3}{*}{} & & & 1.000 & $\begin{array}{c}\text { Management commitments and } \\
\text { support }\end{array}$ \\
\cline { 2 - 6 } & & 1.000 & $0.880^{* *}$ & $0.769^{* *}$ & Feedback and measurement \\
\cline { 2 - 6 } & 1.000 & $0.814^{* *}$ & $0.829^{* *}$ & $0.685^{* *}$ & Continues improvement \\
\hline 1.000 & $0.815^{* *}$ & $0.770^{* *}$ & $0.799^{* *}$ & $0.738^{* *}$ & HR \\
\hline
\end{tabular}

Table (2) shows that the highest correlation coefficient was between the two variables (feedback and measurement) and (continuous improvement), which reached $(0.880)$, which is greater than $(0.80)$, this may indicate the existence of the phenomenon of multiple linear correlation between the variables. The value of the 
correlation coefficient exceeding 0.80 is an indication of the problem of multiple linear high correlations.

To confirm the previous result, the coefficient of variance inflation was calculated for each of the independent variables to ensure a multiple linear correlation. The results were as follows:

Table 3. Multiple correlation test results between independent variables

\begin{tabular}{|c|c|c|}
\hline Tolerance & VIF & Variable \\
\hline 0.324 & 3.082 & Management commitments and support \\
\hline 0.170 & 5.866 & Feedback and measurement \\
\hline 0.178 & 5.607 & Continues improvement \\
\hline 0.228 & 4.386 & HR \\
\hline 0.259 & 3.862 & Operation and systems \\
\hline
\end{tabular}

Table (3) shows that the values of the variance inflation factor were all greater than the number 1 and less than the number 10, and the value of (Tolerance) was limited between the number 0.1 and the number 1 , which indicates that there is no problem of multiple linear correlation between the variables of the study.

\subsection{Validity and Stability of the Study Tool}

The study tool has been subjected to a number of tests as follows:

-The questionnaire of the study instrument: The questionnaire was presented to a group of specialized arbitrators in order to express their opinion and in the light of the suggestions and observations made by the arbitrators, the researcher made the required adjustments. A number of observations were taken, which included an amendment to the wording of some paragraphs in terms of construction, language and content.

-Cronbach Alpha Coefficient was calculated to ensure the reliability and stability of the scale of the study variables and dimensions and the study tool as a whole, to determine the consistency of the answers; the results were as follows:

Table 4. Coherence coefficient values for the study instrument paragraphs

\begin{tabular}{|c|c|c|c|}
\hline Alpha value & Number of paragraphs & Dimension & Number \\
\hline 0.863 & 6 & support and commitment of senior management & 1 \\
\hline 0.941 & 6 & feedback and Measurement & 2 \\
\hline 0.912 & 6 & Continuous Improvement & 3 \\
\hline 0.907 & 6 & Human Resources & 4 \\
\hline 0.864 & 6 & Processes and Systems & 5 \\
\hline 0.972 & 30 & \multicolumn{2}{|l|}{ Sigma Six Standards } \\
\hline 0.893 & 6 & Response & 6 \\
\hline 0.790 & 6 & Reliability & 7 \\
\hline 0.873 & 6 & Intangibility & 8 \\
\hline 0.923 & 18 & \multicolumn{2}{|l|}{ Health services quality dimensions } \\
\hline 0.973 & 48 & \multicolumn{2}{|l|}{ All paragraphs } \\
\hline
\end{tabular}

From Table (4), the values of the internal coefficient of Cronbach's alpha coherence for the study instrument ranges $(0.790-0.972)$, and the value of alpha for all paragraphs was $(0.973)$. Study, the reliability and reliability of the study tool for statistical analysis.

\section{Data Analysis and Hypothesis Testing}

\subsection{Characteristics of Sample Study}

This section includes a description of the demographic and demographic characteristics of the study sample. 
Table 5. Duplicates and percentages of the demographic and demographic characteristics of the study sample:

\begin{tabular}{|c|c|c|c|}
\hline Percentage & Frequency & Category & \multirow{2}{*}{ Gender } \\
\hline 61.0 & 25 & Male & \\
\hline 39.0 & 16 & Female & \multirow{2}{*}{ Job Title } \\
\hline 100 & 41 & Total & \multirow{2}{*}{ Years of senior } \\
& management \\
experience
\end{tabular}

It is clear from Table (5) that the category (males) constituted the largest proportion of the sample of the study sample, where they reached (61.0\%), while the category (females) accounted for (39.0\%) of the study sample, and this indicates that the vast majority Of the workers at the higher administrative levels are males, this may be due to the precedence of men for women to the labor market, and given the data and requirements of leadership and administrative positions, which may not be available to females.

And that the largest proportion of the sample of the study sample (Director), which reached (82.9\%), and this corresponds to the nature of the organizational pyramid in modern organizations, where the number increases as we move to the base of the pyramid, and vice versa.

The sample (15 years and above) constituted the largest percentage of the sample (36.5\%), followed by the experience category (10 - less than 15 years), which amounted to (29.3\%). An indication that the senior management in the Jordanian Ministry of Health has sufficient experience to assume senior management positions and carry out their duties and duties and reflects their ability to absorb and quickly understand the Sigma Six standards.

Finally, we find that the category of holders of the first university degree (bachelor) has made up the majority of the sample of the study, where the proportion $(58.5 \%)$ and this indicates a good percentage of the higher academic levels within the higher management levels.

\subsection{Analysis of Study Tool Paragraphs}

First: Description of Independent Variables, Six Sigma Method Criteria:

To compare the dimensions of the Six Sigma Curriculum Standards, the following table was prepared:

Table 6. Arithmetic averages, standard deviations, grades and relative importance of Sigma Six standards

\begin{tabular}{|c|c|c|c|r|c|}
\hline $\begin{array}{c}\text { relative } \\
\text { importance }\end{array}$ & rank & $\begin{array}{c}\text { standard } \\
\text { deviation }\end{array}$ & Arithmetic & Variable & Number \\
\hline medium & 3 & 0.703 & 2.817 & top management commitment and support & 1 \\
\hline medium & 2 & 0.921 & 3.024 & Intermediate feedback and measurement & 2 \\
\hline medium & 1 & 0.824 & 3.093 & Continuous Improvement & 3 \\
\hline medium & 4 & 0.813 & 2.659 & Processes and systems & 4 \\
\hline medium & 5 & 0.758 & 2.654 & Human Resources & 5 \\
\hline medium & & 0.734 & 2.850 & Six Sigma curriculum standards \\
\hline
\end{tabular}

We note from the previous table that the overall average of the Sigma Six curriculum standards in terms of relative importance is average, where the average was (2.850) and a standard deviation of (0.734). After (continuous improvement) was ranked first with an average of (3.093) and standard deviation (0.824) and medium relative importance, while (human resources) was ranked last with an average of (2.654) and standard deviation (0.758) and of relative importance. 
- Description of dependent variables, quality of health services:

To compare the dimensions of the quality of health services, the following table was prepared:

Table 7. Arithmetic averages, standard deviations, grades and relative importance of health service quality dimensions

\begin{tabular}{|c|c|c|c|c|c|}
\hline Relative importance & Rank & Standard Deviation & Arithmetic & Variable Mean & Number \\
\hline Medium & 2 & 0.735 & 3.008 & Response & 1 \\
\hline Medium & 1 & 0.641 & 3.085 & Tangibility & 2 \\
\hline Medium & 3 & 0.651 & 2.967 & Reliability & 3 \\
\hline Medium & & 0.585 & 3.020 & \multicolumn{2}{|c|}{ Quality of health services } \\
\hline
\end{tabular}

We note from the previous table that the overall average of the quality of health services in terms of relative importance is average, where the overall average (3.020) and standard deviation (0.585). After (tangibility) was ranked first with an arithmetic mean of (3.085) and standard deviation (0.641) and medium relative importance, while (reliability) was ranked last with an arithmetic mean (2.967) and standard deviation (0.651) and of relative importance.

\subsection{Test Hypotheses of the Study}

The main hypothesis:

:H0 "There is no statistically significant effect at the level of significance $(\mathrm{P} \leq 0.050)$ of the Sigma Six Criteria with its combined dimensions (management commitment and support, reverse feeding and measurement, continuous improvement, processes and systems, human resources) on improving the quality of health services by its dimensions(Tangible, responsive) at the Jordanian Ministry of Health.

To test the main hypothesis and its subdivisions, multiple linear regression analysis was used.

H01: There is no statistically significant effect at the level of significance $(\mathrm{P} \leq 0.050)$ of the Sigma Six curriculum standards by its combined dimensions on the response in improving the quality of health services in the Ministry of Health.

Table 8. Impact test results (Six Sigma curriculum criteria) on response

\begin{tabular}{|c|c|c|c|c|c|c|c|c|c|c|}
\hline \multicolumn{5}{|c|}{ Coefficients } & \multicolumn{3}{|c|}{ ANOVA } & \multicolumn{2}{|c|}{$\begin{array}{c}\text { Model } \\
\text { Summery } \\
\end{array}$} & \multirow[t]{2}{*}{ variable } \\
\hline Sig t* & $\mathrm{T}$ & $\begin{array}{c}\text { Standard } \\
\text { error }\end{array}$ & B & Statement & Sig F* & Df & $\mathrm{F}$ & $\mathrm{R}^{2}$ & $\mathrm{R}$ & \\
\hline 0.001 & 3.476 & 0.192 & 0.669 & $\begin{array}{c}\text { Senior management } \\
\text { commitment and } \\
\text { support } \\
\end{array}$ & \multirow[t]{5}{*}{0.000} & \multirow[t]{5}{*}{5} & \multirow[t]{5}{*}{11.199} & \multirow[t]{5}{*}{0.615} & \multirow[t]{5}{*}{0.784} & \multirow[t]{5}{*}{ Response } \\
\hline 0.772 & 0.291 & 0.203 & 0.059 & $\begin{array}{l}\text { Feedback and } \\
\text { Measurement }\end{array}$ & & & & & & \\
\hline 0.012 & 2.646 & 0.221 & 0.586 & $\begin{array}{l}\text { Continuous } \\
\text { Improvement }\end{array}$ & & & & & & \\
\hline 0.458 & 0.750 & 0.198 & 0.149 & $\begin{array}{l}\text { Operations and } \\
\text { Systems }\end{array}$ & & & & & & \\
\hline 0.064 & 1.912 & 0.200 & 0.382 & Human Resources & & & & & & \\
\hline
\end{tabular}

*The effect is statistically significant at $(\mathrm{p} \leq 0.05)$.

The results of table $(8)$ indicate that the correlation coefficient $(\mathrm{R}=0.784)$ indicates the relationship between the independent variables and the dependent variable, and the effect of the independent variables (Sigma Six Criteria criteria) on the dependent variable (response) is statistically significant, where the value of F calculated (11.199), and the level of significance ( $\mathrm{Sig}=0.000$ ), which is less than 0.05 , where it appeared that the value of the coefficient of determination ( $\mathrm{R} 2=0.615)$ It indicates that $(61.5 \%)$ of the variance in (response) can be explained by the variance in ( The Sigma methodology criteria are six (combined), and the table of transactions showed that the value of B at the dimension (commitment and support of senior management) was (0.669) and the value of $\mathrm{t}$ at (3.476), and the level of significance ( $\mathrm{Sig}=0.001$ ), indicating that the effect of this dimension is significant. And that the value of B at the dimension (feedback and measurement) was (0.059) and the value of $t$ at $(0.291)$, and the level of significance $(\mathrm{Sig}=0.772)$, which indicates that the effect of this dimension is not 
significant. The value of B at (Continuous Improvement) was (0.586) and the value of $t$ at (2.646), and the level of significance ( $\mathrm{Sig}=0.012$ ), which indicates that the effect of this dimension is significant. The value of B at the dimension (processes and systems) $(0.149)$ and $t$ at $(0.750)$, and the level of significance $(\mathrm{Sig}=0.458)$, which indicates that the effect of this dimension is not significant. The value of $B$ at the dimension (HR)

(0.382)and the value of $\mathrm{t}$ is (1.912), with a level of significance ( $\mathrm{Sig}=0.064)$, which indicates that the effect of this dimension is not significant

Based on the above, we reject the first nihilistic hypothesis and accept the alternative hypothesis:

"There is a statistically significant impact at the significant level $(\mathrm{P} \leq 0.050)$ of the Sigma Six curriculum standards by its combined dimensions (commitment and support of senior management, feedback and measurement, continuous improvement, processes and systems, human resources) on the response in improving the quality of health services in the Ministry of Health".

H02: There is no statistically significant effect at the significant level $(\mathrm{P} \leq 0.050)$ of the Sigma Six curriculum standards by its combined dimensions (commitment and support of senior management, reverse nutrition and measurement, continuous improvement, processes and systems, human resources) on the reliability in improving the quality of health services in the ministry of health.

Table 9. Impact test results (Sigma Six curriculum criteria) on reliability

\begin{tabular}{|c|c|c|c|c|c|c|c|c|c|c|}
\hline \multicolumn{5}{|c|}{ Coefficients } & \multicolumn{3}{|c|}{ ANOVA } & \multicolumn{2}{|c|}{$\begin{array}{c}\text { Model } \\
\text { Summery }\end{array}$} & \multirow[t]{2}{*}{ variable } \\
\hline Sig t* & $\mathrm{T}$ & $\begin{array}{c}\text { Standard } \\
\text { error }\end{array}$ & B & Statement & Sig F* & Df & $\mathrm{F}$ & $\mathrm{R}^{2}$ & $\mathrm{R}$ & \\
\hline 0.296 & 1.061 & 0.200 & 0.213 & $\begin{array}{c}\text { support of top } \\
\text { management }\end{array}$ & \multirow[t]{5}{*}{0.000} & \multirow[t]{5}{*}{5} & \multirow[t]{5}{*}{6.173} & \multirow[t]{5}{*}{0.469} & \multirow[t]{5}{*}{0.685} & \multirow[t]{5}{*}{ Reliability } \\
\hline 0.503 & 0.677 & 0.211 & 0.143 & Feedback & & & & & & \\
\hline 0.264 & 1.134 & 0.230 & 0.261 & $\begin{array}{l}\text { Continuous } \\
\text { Improvement }\end{array}$ & & & & & & \\
\hline 0.074 & 1.841 & 0.207 & 0.380 & $\begin{array}{c}\text { Operations and } \\
\text { Systems }\end{array}$ & & & & & & \\
\hline 0.252 & 164. & 0.208 & 0.242 & Human Resources & & & & & & \\
\hline
\end{tabular}

*The effect is statistically significant at $(\mathrm{p} \leq 0.05)$.

The results of table $(9)$ indicate that the correlation coefficient $(\mathrm{R}=0.685)$ refers to the relationship between independent variables and dependent variable, and the effect of independent variables (Sigma Six Criteria criteria) on the dependent variable (reliability) is statistically significant, where the value of F calculated (6.173), and the level of significance $(\mathrm{Sig}=0.000)$ which is less than 0.05 , where the value of the coefficient of determination $(\mathrm{R} 2=0.469)$ It indicates that $(46.9 \%)$ of the variance in (reliability) can be explained by the variance in ( Six Sigma curriculum criteria) combined.

The transactions table showed that the value of $\mathrm{B}$ at the dimension (commitment and support of senior management) was (0.213) and the value of $\mathrm{t}$ at (1.061), and the level of significance ( $\mathrm{Sig}=0.296$ ), which indicates that the impact of this dimension is not significant. The value of B at the dimension (feedback and measurement) was (0.143) and the value of $t$ at $(0.677)$, and the level of significance (Sig $=0.503)$, which indicates that the effect of this dimension is not significant. The value of B at (continuous improvement) was $(0.261)$ and $t$ at $(1.134)$, and the level of significance ( $\mathrm{Sig}=0.264)$, which indicates that the effect of this dimension is not significant. The value of $\mathrm{B}$ at the dimension (processes and systems) (0.380) and $\mathrm{t}$ at (1.841), and the level of significance $(\mathrm{Sig}=0.074)$, which indicates that the effect of this dimension is not significant. The value of B at (human resources) dimension (0.242) and $\mathrm{t}$ at (1.164), and the level of significance ( $\mathrm{Sig}=$ 0.252 ), which indicates that the effect of this dimension is not significant.

Based on the above, we reject the second hypothesis and accept the alternative hypothesis:

"There is a statistically significant impact at the significant level $(\mathrm{P} \leq 0.050)$ of the Sigma Six curriculum standards by its combined dimensions (commitment and support of senior management, reverse feeding and measurement, continuous improvement, processes and systems, human resources) on the reliability in improving the quality of health services in the Ministry of Health".

H03: There is no statistically significant effect at the significant level $(\mathrm{P} \leq 0.050)$ of the Sigma Six curriculum standards by its combined dimensions (commitment and support of senior management, reverse feeding and 
measurement, continuous improvement, processes and systems, human resources) on the concreteity in improving the quality of health services in the ministry of health.

Table 10. The results of the impact test (Six Sigma Curriculum Standards) on concrete

\begin{tabular}{|c|c|c|c|c|c|c|c|c|c|c|}
\hline \multicolumn{5}{|c|}{ Coefficients } & \multicolumn{3}{|c|}{ ANOVA } & \multicolumn{2}{|c|}{ Model Summery } & \multirow[t]{2}{*}{ variable } \\
\hline Sig t* & $\mathrm{T}$ & $\begin{array}{l}\text { Standard } \\
\text { error }\end{array}$ & B & Statement & Sig F* $^{*}$ & Df & $\mathrm{F}$ & $\mathrm{R}^{2}$ & $\mathrm{R}$ & \\
\hline 0.253 & 1.161 & 0.210 & 0.244 & $\begin{array}{c}\text { support of } \\
\text { top } \\
\text { management }\end{array}$ & 0.002 & 5 & 4.633 & 0.398 & 0.631 & Tangible \\
\hline 0.290 & 1.074 & 0.221 & 0.237 & Feedback & & & & & & \\
\hline 0.090 & 1.742 & 0.242 & 0.421 & $\begin{array}{l}\text { Continuous } \\
\text { Improvement }\end{array}$ & & & & & & \\
\hline 0.659 & 0.445 & 0.217 & 0.096 & $\begin{array}{c}\text { Operations } \\
\text { and Systems }\end{array}$ & & & & & & \\
\hline 0.008 & 2.830 & 0.218 & 0.617 & $\begin{array}{c}\text { Human } \\
\text { Resources }\end{array}$ & & & & & & \\
\hline
\end{tabular}

The effect is statistically significant at $(\mathrm{p} \leq 0.05)$.

The results of Table (10) indicate that the correlation coefficient $(\mathrm{R}=0.631)$ indicates the relationship between the independent variables and the dependent variable, and that the effect of the independent variables (Sigma Six Criteria Methods) on the dependent variable (tangibility) is statistically significant. F calculated (4.633), and the level of significance ( $\mathrm{Sig}=0.002$ ), which is less than 0.05 , where the value of the coefficient of determination $(\mathrm{R} 2=0.398)$ It indicates that $(39.8 \%)$ of the variance in (tangibility) can be explained by the variation in ( Six Sigma curriculum criteria) combined.

The table of transactions showed that the value of B at the dimension (commitment and support of senior management) was (0.244) and the value of $t$ at (1.161), and the level of significance $(\mathrm{Sig}=0.253)$, which indicates that the impact of this dimension is not significant. The value of B at the dimension (feedback and measurement) was (0.237) and the value of $\mathrm{t}$ at (1.074), and the level of significance $(\mathrm{Sig}=0.290)$, which indicates that the effect of this dimension is not significant. The value of B at (Continuous Improvement) was $(0.421)$ and $\mathrm{t}$ at (1.742), with a significance level ( $\mathrm{Sig}=0.090)$, which indicates that the effect of this dimension is not significant. The value of $\mathrm{B}$ at the dimension (processes and systems) (0.096) and $\mathrm{t}$ at $(0.445)$, and the level of significance $(\mathrm{Sig}=0.659)$, which indicates that the effect of this dimension is not significant. The value of $\mathrm{B}$ at (human resources) dimension (0.617) and t value at $(2.830)$, and the level of significance $(\mathrm{Sig}=0.008)$, which indicates that the effect of this dimension significant.

Based on the above, we reject the third hypothesis and accept the alternative hypothesis:

"There is a statistically significant impact at the level of significance (P.00.050) of the Sigma Six curriculum standards by its combined dimensions on the concretely in improving the quality of health services in the Ministry of Health"

To test the first major hypothesis, multiple regression analysis was used. The results were as follows: 
Table 11. Results of the impact test (Six Sigma Curriculum Standards) on the quality of health services

\begin{tabular}{|c|c|c|c|c|c|c|c|c|c|c|}
\hline \multicolumn{5}{|c|}{ Coefficients } & \multicolumn{3}{|c|}{ ANOVA } & \multicolumn{2}{|c|}{ Model Summery } & \multirow[t]{2}{*}{ variable } \\
\hline $\begin{array}{c}\mathrm{Sig} \\
\mathrm{t}^{*}\end{array}$ & $\mathrm{~T}$ & $\begin{array}{c}\text { Standard } \\
\text { error }\end{array}$ & B & Statement & $\operatorname{Sig} \mathrm{F}^{*}$ & Df & $\mathrm{F}$ & $\mathrm{R}^{2}$ & $\mathrm{R}$ & \\
\hline 0.019 & 2.450 & 0.153 & 0.375 & $\begin{array}{c}\text { support of } \\
\text { top } \\
\text { management }\end{array}$ & \multirow[t]{5}{*}{0.000} & \multirow[t]{5}{*}{5} & \multirow[t]{5}{*}{11.207} & \multirow[t]{5}{*}{0.616} & \multirow[t]{5}{*}{0.785} & \multirow{5}{*}{$\begin{array}{c}\text { Health } \\
\text { Services } \\
\text { Quality and } \\
\text { Commitment }\end{array}$} \\
\hline 0.511 & 0.664 & 0.161 & 0.107 & Feedback & & & & & & \\
\hline 0.022 & 2.399 & 0.176 & 0.423 & $\begin{array}{c}\text { Continuous } \\
\text { Improvement }\end{array}$ & & & & & & \\
\hline 0.367 & 0.914 & 0.158 & 0.144 & $\begin{array}{c}\text { Operations } \\
\text { and Systems }\end{array}$ & & & & & & \\
\hline 0.013 & 2.602 & 0.159 & 0.414 & $\begin{array}{c}\text { Human } \\
\text { Resources }\end{array}$ & & & & & & \\
\hline
\end{tabular}

*The effect is statistically significant at $(\mathrm{p} \leq 0.05)$.

The results of Table (11) indicate that the correlation coefficient $(\mathrm{R}=0.785)$ indicates the relationship between the independent variables and the dependent variable. The effect of the independent variables (Sigma Six Criteria criteria) on the dependent variable (health services quality) is statistically significant. The calculated value of $\mathrm{F}$ was (11.207), and the significance level $(\mathrm{Sig}=0.000)$ is less than 0.05 , where the value of the coefficient of determination $(\mathrm{R} 2=0.616)$, which indicates that $(61.6 \%)$ of the variation in (quality of health services) can be explained by during the contrast in (Six Sigma curriculum criteria) combined.

The transactions table showed that the value of $\mathrm{B}$ at the dimension (commitment and support of senior management) was (0.375) and the value of $\mathrm{t}$ at $(2.450)$, and the level of significance $(\mathrm{Sig}=0.019)$, which indicates that the effect of this dimension is significant. The value of $\mathrm{B}$ at the dimension (feedback and measurement) was (0.107) and the value of $\mathrm{t}$ at $(0.664)$, and the level of significance $(\mathrm{Sig}=0.511)$, which indicates that the effect of this dimension is not significant. The value of B at (Continuous Improvement) was $(0.423)$ and $\mathrm{t}$ at (2.399), and the level of significance ( $\mathrm{Sig}=0.022)$, which indicates that the effect of this dimension is significant. The value of B at (processes and systems) dimension (0.144) and t at (0.914), and the level of significance ( $\mathrm{Sig}=0.367)$, which indicates that the effect of this dimension is not significant. The value of $\mathrm{B}$ at (HR) dimension (0.414) and $\mathrm{t}$ at (2.602), and the level of significance ( $\mathrm{Sig}=0.013$ ), which indicates that the effect of this dimension significant.

Based on the above, we reject the main hypothesis and accept the alternative hypothesis:

"There is a statistically significant effect at the level of significance $(\mathrm{P} \leq 0.050)$ of the Sigma Six Approach dimensions by its combined dimensions (management commitment and support, reverse feeding and measurement, continuous improvement, processes and systems, human resources) on improving the quality of health services by collecting them at the Jordanian Ministry of Health".

\section{Discuss and Conclusion}

\subsection{Descriptive Analysis of Study Variables (Relative Importance of Study Variables}

1. The results of the descriptive analysis of the independent variable (Sigma Six Criteria) showed, that the Sigma Six Criteria in terms of relative importance was average, as well as the analysis showed, that after (Continuous Improvement) came first and with relative importance, while (Human Resources) came last. And of relative importance.

2. The results of the descriptive analysis of the dependent variable (the quality of health services) showed that the overall average of the quality of health services, by dimensions in terms of relative importance, was the average, as well as the analysis showed that after (tangibility) came first, and with relative importance, while came after (reliability) in The last rank is of relative importance.

\section{Recommendations}

Based on the previous results, the researcher recommended the following:

1. The Ministry of Health should pay more attention to the concept, and criteria of Sigma Six curriculum, and its application at the level of top management, and its role in the success of this curriculum.

2. Train all employees in the top management and various levels in these departments on the Sigma Six, 
standards and provide the necessary financial support, to motivate the employees by linking the use of Sigma Six standards, with material and moral incentives.

3. The top management must set their priorities to develop and improve, the service and adopt new initiatives contribute, to improve the levels of service provided in the ministry.

4. The need to create specialized administrative units to receive complaints and suggestions, from the recipients of the service, and give them the opportunity to contribute, to the development and improvement, of performance and service by providing an information system, on the service provided, which helps in decision-making processes and improve.

5. Supplying the ministry, with its human needs of medical and technical cadres, expanding the residency programs and providing a system of scholarship for comprehensive medical specialties.

6. The Ministry should carry out more future studies that show the positive effects of the application of the Sigma Six criteria on the financial costs of health services and study the possibility of applying these Sigma Six approach to human resources management functions.

7. Researchers should conduct future studies on other variables.

\section{References}

Abdul, R., \& Omar, Y. I. (2014). Possibility of Using Six Sigma in Improving the Quality of Banking Services in Islamic Banks (Doctoral dissertation, International Islamic Science University).

Ahmad, S. A. (2017). The role of costing quality in achieving the objectives of continuous improvement. Jordan, Amman: Dar Al-Raneem for Publishing and Distribution.

AL- qatawneh, L., Abdallah, A. A. A., \& Salam, Z. (2019). Six Sigma Application in Healthcare Logistics: A Framework and A Case Study. Journal of Healthcare Engineering, 2019, 12. https://doi.org/10.1155/2019/9691568

Al-Dararaka, M., \& Shibli, T. (2002). Quality in Modern Organizations. Jordan, Amman: Safa Publishing House.

Al-Najjar, F. J., Al-Najjar, N. J., \& Al-Zoubi, M. R. (2018). Scientific Research Methods - An Applied Perspective.

Alnjar, S. M. A. (2011). The implementation of six sigma and its effect on knowledge creation: the case of Jordan healthcare hospital (Master thesis, Faculty of Economics and Administrative Sciences, Yarmouk University, Jordan).

Al-Nuaimi, M. A., \& Sweis, R. K. (2008). Sigma Six Accuracy in Quality Management Concepts and Applications. Jordan, Amman: Athraa Publishing and Distribution.

Al-Omari, A. M. (2015). The impact of critical success factors in the application of graceful hexagonal diffraction in service organizations: case studies (Doctoral thesis, Faculty of Graduate Studies, University of International Islamic Sciences. Jordan).

Al-Otaibi, A. G. D. (2017). Requirements for the application of the principles of Sigma Six "according to the model DIMAC" DMAIC "at the University of Shaqra from the point of view of its leaders. Journal of Studies, Educational Sciences, University of Jordan.

Alrawai, S. A. A. G. (2011). Using Six Sigma Approach in Quality Control of Internal Audit, Field Study on Private Award Winning Hospitals in Amman Governorate (Master's Thesis, Accounting Department, Faculty of Business, Middle East University).

Al-Tai, Y. H., Ajili, M. A., \& Hakim, L. A. (2009). Quality Management Systems in Productive and Service Organizations. Jordan, Amman: Dar Al Yazouri Scientific Publishing and Distribution.

Awad, M. I. (2011). Application of Sigma Six in service and industrial organizations. Amman: Dar Al Fikr Publishers and Distributors.

Bakri, T. (2005). Health Services Marketing. Jordan, Amman: Dar Al Yazouri Scientific Printing \& Publishing.

Issawi, N. S., \& Al-Tahan, E. A. K. (2018). Intellectual Capital as an intermediary variable between the quality of career and the Sigma Six methodology applied to workers in the Ministry of Health in Saudi Arabia. Arab Journal of Management, 38(3), 189.

Jaber, A. (2015). The reality of human resources management according to the European model of excellence in the Palestinian government sector and ways to develop (Unpublished master's thesis). Al-Aqsa University, 
Gaza.

Jordanian Ministry of Health Strategy for the years. (2018-2020).

Khalil, K. M. (2014). Requirement for implementing six sigma approach in Jordanian pharmaceutical industry (Master Thesis, Faculty of Economics and Administrative Sciences, Yarmouk University, Jordan).

Melhem, Y. S. (2014). 6 Sigma from a qualitative perspective. Jordan, Amman: Wael Publishing.

Noor, A. N. et al. (2012). Using the Six Sigma Approach in Quality Control Internal Audit. 11th Annual Scientific Conference "Business Intelligence and Knowledge Economy, Faculty of Economics and Administrative Sciences, Al-Zaytoonah University.

Omari, H. A. O. (2011). The extent of adherence to the standards of adoption of international quality in the health services sector in the Kingdom of Saudi Arabia: a survey study applied to the province of Jeddah. Arab Journal of Management.

Poetry, M. H. H. (2014). The Impact of Using Six Sigma on Customer Value and Satisfaction: A Case Study of a Mobile Security Company (Master Thesis, Business School, Middle East University, Jordan).

Salaymeh, N. (2007). Possibility of Using Six Sigma to Improve Health Performance at Arab Medical Center (Master Thesis, Amman Arab University for Graduate Studies, Jordan).

Samiha, S. A. R. (2017). The Extent of Sigma Six Approach in the Major Food Manufacturing Companies in the West Bank (Master Thesis, Faculty of Graduate Studies, Hebron University, Palestine).

Sanjak, G. M. (2010). United Nations International Standards Committee for Hospital Accreditation Between Theory and Practice.

Tawfik, A. R. (2008). 6 Sigma and the matrix of balanced performance for those who seek optimal performance. Egypt, Giza: Center of professional expertise for management.

Victory, M. M. (2009). Introduction to Total Quality Management and Sigma Six. Giza: International Publishing and Distribution House.

\section{Copyrights}

Copyright for this article is retained by the author(s), with first publication rights granted to the journal.

This is an open-access article distributed under the terms and conditions of the Creative Commons Attribution license (http://creativecommons.org/licenses/by/4.0/). 